\title{
Percutaneous retrieval of a detached rotational atherectomy burr
}

\author{
Michał Kosowski ${ }^{1,2}$, Wojciech Zimoch ${ }^{1,2}$, Piotr Kübler², Marcin Wojtczak², Artur Telichowski², Krzysztof Reczuch ${ }^{1,2}$ \\ 1Department of Heart Diseases, Faculty of Health Sciences, Wroclaw Medical University, Wroclaw, Poland \\ 2Department of Cardiology, Centre for Heart Diseases, Military Hospital, Wroclaw, Poland
}

Postep Kardiol Inter 2013; 9, 3 (33): 301-303

DOI: 10.5114/pwki.2013.37516

\begin{abstract}
Rotablation (rotational atherectomy) is an acknowledged method of percutaneous treatment of highly calcified coronary artery lesions that cannot be treated with traditional angioplasty. The complexity of the technique and usage of very specific equipment can contribute to the development of uncommon complications. We present a case of percutaneous retrieval of a damaged rotational atherectomy burr in a 74-year-old male patient.
\end{abstract}

Key words: rotablation, rotational atherectomy, intracoronal foreign body removal.

\section{Introduction}

Rotational atherectomy is an acknowledged method of percutaneous treatment of highly calcified or fibrotic coronary lesions that cannot be treated with traditional angioplasty [1]. The European Society of Cardiology recommends using rotational atherectomy to prepare lesions that cannot be crossed with the balloon catheter or adequately dilated (recommendation class I, evidence level C) [2]. The complexity of the technique and usage of very specific equipment can contribute to the development of uncommon complications.

We present a case of successful percutaneous retrieval of a damaged rotational atherectomy burr in a 74-year-old man who underwent a procedure on the right coronary artery.

\section{Case report}

A 74-year-old man with ESC class 2 arterial hypertension, type 2 diabetes mellitus, K/DOQI (Kidney Disease Outcomes Quality Initiative) stage 4 chronic kidney disease, with a history of three non-ST segment elevation myocardial infarctions (NSTEMI) in 1999, 2000 and 2009, coronary artery bypass surgery (CABG) with LIMA-LAD, Ao-SVG-Cx/OM, AoSVG-RCA grafts in 2001, after ischemic stroke, right internal carotid and right renal atherectomy was admitted to the Cardiology Department of the $4^{\text {th }}$ Military Hospital in Wro- claw in order to perform coronary angiography. In anamnesis the patient suffered from stable coronary disease in CCS class II, with escalation of symptoms to CCS class III/IV about 2 weeks before admission. Physical examination revealed no significant abnormalities. ECG showed left axis deviation, normal sinus rhythm 70/min, QS complex in leads V1-V3, and flat-negative T waves in leads I and aVL. BP was 105/70 mm Hg. Laboratory tests revealed normocytic anemia ( $\mathrm{Hb} 11.1 \mathrm{~g} / \mathrm{dl}$, HCT 32.5\%), estimated glomerular filtration rate (eGFR) $36 \mathrm{ml} / \mathrm{min} / 1.73 \mathrm{~m}^{2}$, and troponin levels were in the normal range.

Coronary angiography showed numerous calcifications in both coronary arteries, left main (LM) critically stenosed in the distal segment, ostial stenosis and occlusion of the left anterior descending (LAD) artery after the first diagonal (Dg) branch, and circumflex artery (Cx) occluded in the medial segment. The dominant right coronary artery (RCA) was stenosed in the proximal segment with a highly calcified lesion (Figure 1), and the distal segments were stenosed to $30-40 \%$. Patent grafts - LIMA-LAD, Ao-SVG$\mathrm{Cx} / \mathrm{OM}$ - were also visible; the graft to the RCA was occluded proximally. The patient was qualified for RCA angioplasty using rotational atherectomy.

A 7 F AL1 guiding catheter was used to intubate the RCA, Cruiser Hydro ES-F (Biotronik) and RotaWire Extra Support (Boston Scientific) guidewires were subsequently introduced into the vessel. A temporary pacing electrode was implant-

Corresponding author:

lek. Michał Kosowski, Department of Heart Diseases, Faculty of Health Sciences, Wroclaw Medical University, 5 Weigla St, 50-981 Wroclaw, Poland, tel.: +48 606895 229, e-mail: mkosowski@gmail.com

Received: 24.08. 2012, accepted: 8.08.2013. 


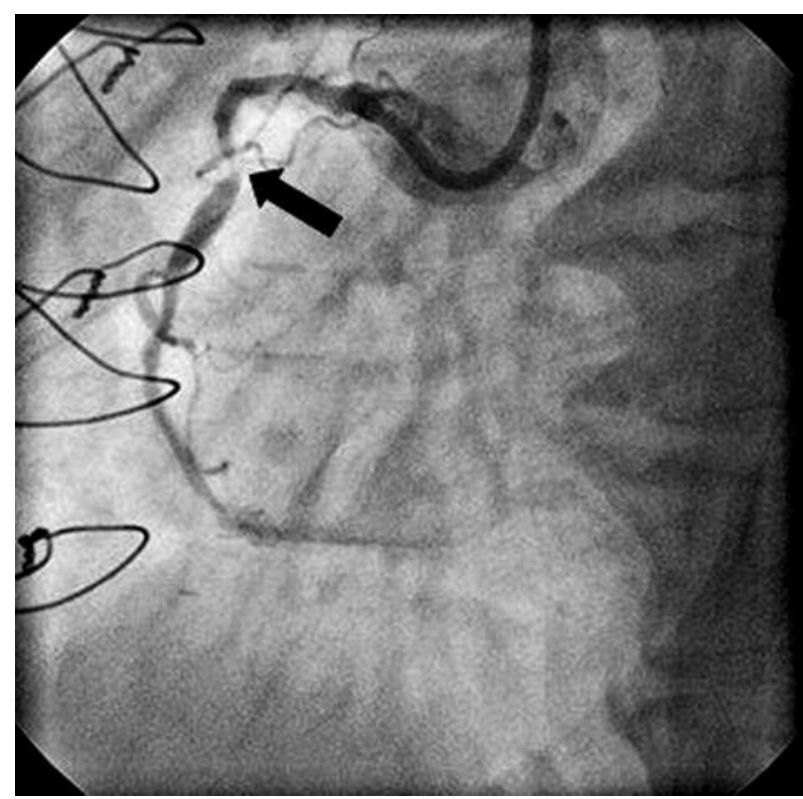

Fig. 1. Right coronary artery with marked stenosis (LAO 45 CRAN 0)

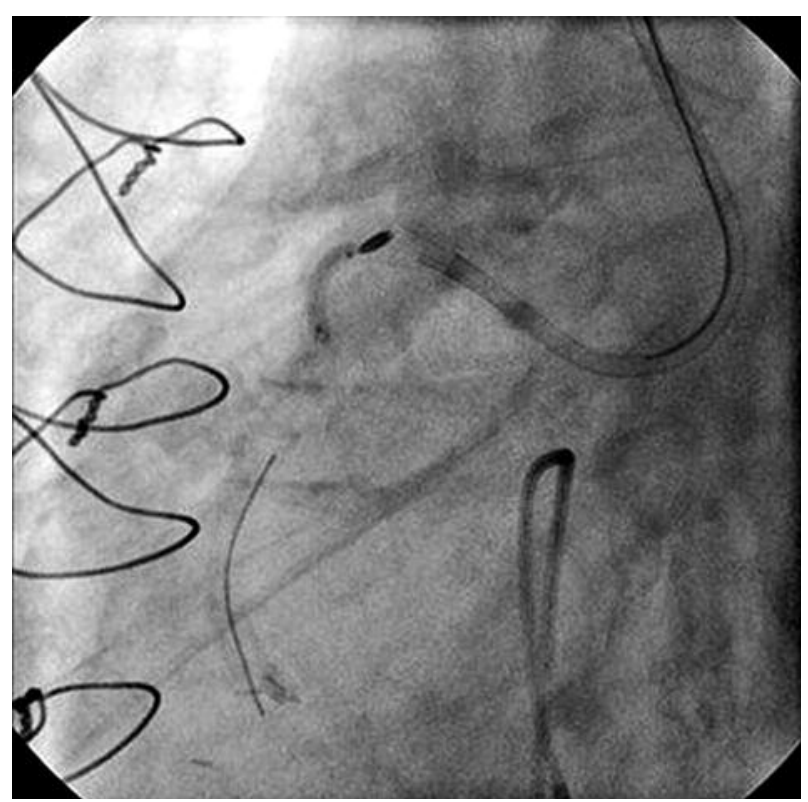

Fig. 3. Coronary balloon dilatated distally to the burr before it was brought back to the guiding catheter (LAO 45 CRAN 0)

ed. A couple of passages with a $1.5 \mathrm{~mm}$ diameter burr (RotaLink Plus, Boston Scientific) at 140000 revolutions per minute (RPM) were made in the area of the highly calcified, proximal lesion of the RCA. A sudden drop of burr rotation speed was observed during the last passage, followed by a complete stop. The operator was unable to restart the rotational atherectomy system. When an attempt to remove the catheter was made, the burr became detached from the catheter and got stuck in the lesion. The flow through

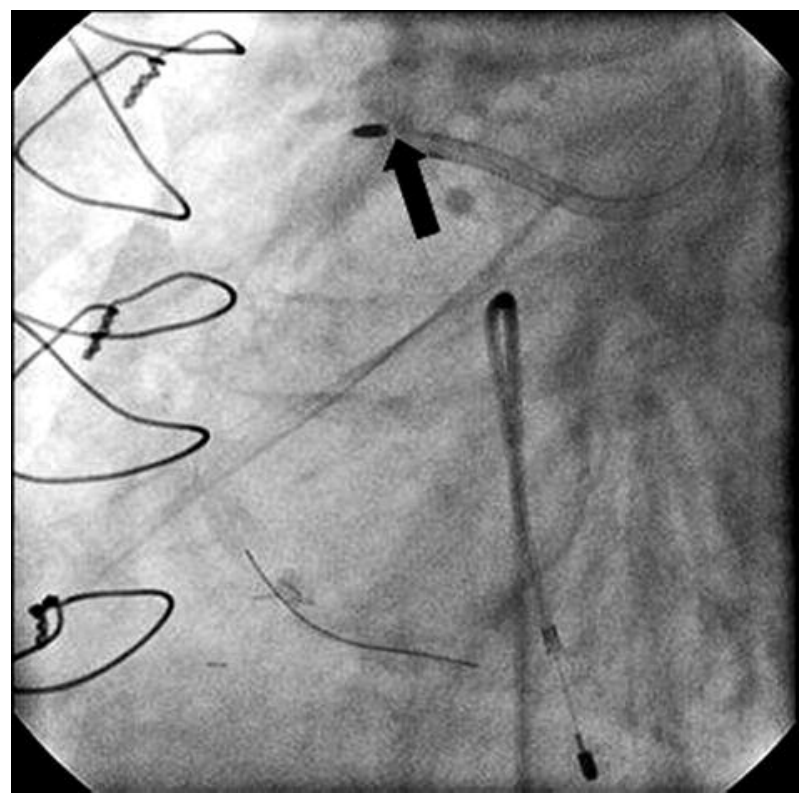

Fig. 2. Damaged rotational atherectomy catheter. The place of burr detachment is marked by an arrow (LAO 45 CRAN 0)

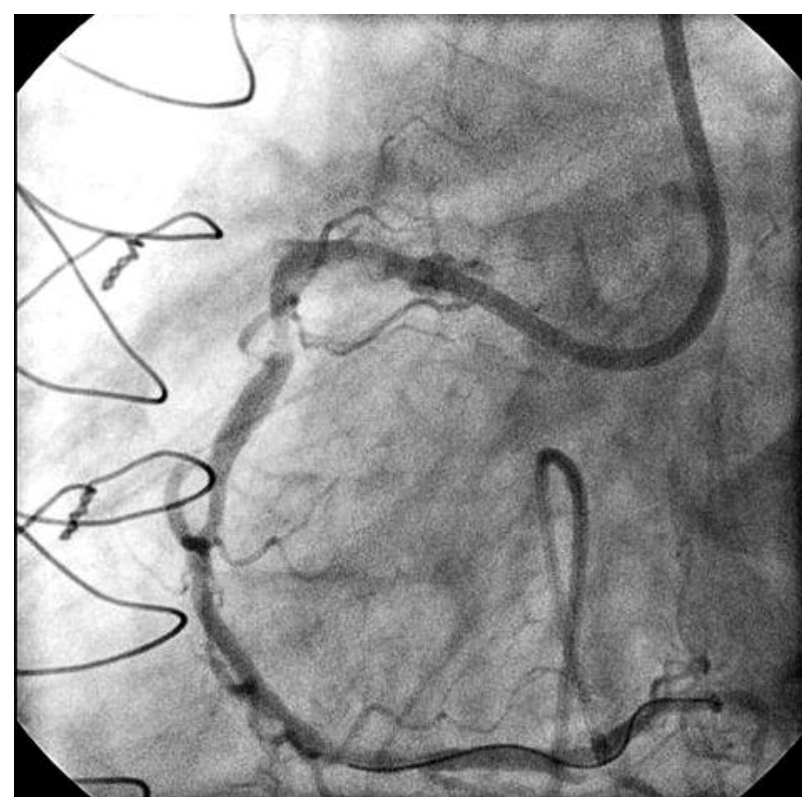

Fig. 4. Preserved flow in RCA after burr retrieval (LAO 45 CRAN 0)

the artery was preserved, though (Figure 2). A decision to remove the detached burr percutaneously, using a balloon catheter, was made. After many attempts a Cruiser Hydro ES-F guidewire and Sprinter Legend RX (Medtronic) $2.0 \mathrm{~mm}$ $\times 10 \mathrm{~mm}$ balloon were successfully introduced. After the balloon inflation it was withdrawn, along with the detached burr, to the guiding catheter (Figure 3). All the equipment was removed en bloc from the patient's body. The procedure was continued, but attempts to dilate the lesion with 
Sprinter Legend RX $1.25 \mathrm{~mm} \times 6 \mathrm{~mm}$ and $2.0 \mathrm{~mm} \times 10 \mathrm{~mm}$ failed. Repeated contrast injection showed preserved flow through the artery (Figure 4). The patient was scheduled for the next, elective attempt of rotational atherectomy. The patient was discharged in satisfactory condition, with normal serum troponin I levels and stable renal function (eGFR $42 \mathrm{ml} / \mathrm{min} / 1.73 \mathrm{~m}^{2}$ ).

\section{Discussion}

A number of complications of intra-coronary interventions are specific for rotational atherectomy procedures [3]. These complications usually involve mechanical interactions between the burr (rotation at high speed) and the artery; there are forces interacting between the individual parts of the system as well. Cases of burr entrapment in the highly calcified lesions and inability to withdraw the burr after passing narrow lesions are well known and have been reported [4-10]. There is also a possibility of guidewire damage done by a burr that remained too long time in the same place and when the treated vessel is tortuous [11, 12]. There are only a few descriptions of complications similar to the one described above (spontaneous burr detachment) available in the literature, mainly in U.S. Federal Food and Drug Administration (FDA) reports [13, 14]. Endo et al. described a quite similar case of burr damage and detachment, but they emphasize the possibility of another cause (i.e. other than the burr wedging in a highly calcified lesion) and do not rule out a mechanical device failure [15]. In that case the operators decided on surgical removal of the parts that remained in the LAD. In our case we could not determine the cause of the burr damage. The procedure was performed by a well-trained, experienced team, and all the equipment recommendations were fulfilled. We decided on percutaneous removal of the damaged parts. Authors of descriptions of removal of intracoronary foreign bodies (damaged wires, stents, balloons, etc.) indicate that various tools (loops, retrieval baskets placed on catheters, forceps, etc.) may be used [16-18]. The operators recognized that the odds in favor of successful retrieval of damaged equipment would be the highest if they used an additional guidewire and balloon. According to our experience, the method is safe, efficacious and does not need sophisticated equipment.

In conclusion, we need to emphasize that a number of complications can occur during intra-coronary interventions, especially when a technique such as rotational atherectomy is used. An individual assessment of every complication and proper actions can help to solve every problem in a minimally invasive way, as described in the case above.

\section{References}

1. Cavusoglu E, Kini AS, Marmur JD, Sharma SK. Current status of rotational atherectomy. Catheter Cardiovasc Interv 2004; 62: 485-498.

2. Wijns W, Kolh P, Danchin N, et al. Guidelines on myocardial revascularization. Eur Heart J 2010; 31: 2501-2555.
3. Warth DC, Leon MB, O'Neill W, et al. Rotational atherectomy multicenter registry: acute results, complications and 6-month angiographic follow-up in 709 patients. J Am Coll Cardiol 1994; 24: 641-648.

4. Cunnington M, Egred M. GuideLiner, a child-in-a-mother catheter for successful retrieval of an entrapped rotablator burr. Catheter Cardiovasc Interv 2011; 79: 271-273.

5. Grise MA, Yeager MJ, Teirstein PS. A case of an entrapped rotational atherectomy burr. Catheter Cardiovasc Interv 2002; 57: 31-33.

6. Hyogo $\mathrm{M}$, Inoue $\mathrm{N}$, Nakamura $\mathrm{R}$, et al. Usefulness of conquest guidewire for retrieval of an entrapped rotablator burr. Catheter Cardiovasc Interv 2004; 63: 469-472.

7. Kaneda H, Saito S, Hosokawa G, et al. Trapped Rotablator: kokesi phenomenon. Catheter Cardiovasc Interv 2000; 49: 82-84.

8. Kimura M, Shiraishi J, Kohno Y. Successful retrieval of an entrapped Rotablator burr using $5 \mathrm{Fr}$ guiding catheter. Catheter Cardiovasc Interv 2011; 78: 558-564.

9. Prasan AM, Patel M, Pitney MR, Jepson NS. Disassembly of a rotablator: getting out of a trap. Catheter Cardiovasc Interv 2003; 59: 463-465.

10. Sakakura K, Ako J, Momomura S. Successful removal of an entrapped rotablation burr by extracting drive shaft sheath followed by balloon dilatation. Catheter Cardiovasc Interv 2011; 78: 567-570.

11. Foster-Smith K, Garratt KN, Holmes DR Jr. Guidewire transection during rotational coronary atherectomy due to guide catheter dislodgement and wire kinking. Cathet Cardiovasc Diagn 1995; 35: 224-227.

12. Woodfield SL, Lopez A, Heuser RR. Fracture of coronary guidewire during rotational atherectomy with coronary perforation and tamponade. Cathet Cardiovasc Diagn 1998; 44: 220-223.

13. U.S. Food and Drug Administration. MAUDE Adverse Event Report. [update 8/24/2011; access 02/19/2012]. Available online: https://www.accessdata.fda.gov/scripts/cdrh/cfdocs/cfmaude/detail. cfm?mdrfoi_id=2256404.

14. U.S. Food and Drug Administration. MAUDE Adverse Event Report. [update 7/21/2011; access 02/19/2012]. Available online: http:// www.accessdata.fda.gov/scripts/cdrh/cfdocs/cfMAUDE/detail.cfm?m drfoi_id=2215081.

15. Endo GJ, Hayase T, Fukushima Y, Shibata Y. Emergent coronary artery bypass grafting after a broken Rotablator drive-shaft. Interact Cardiovasc Thorac Surg 2010; 11: 614-616.

16. Alexiou K, Kappert U, Knaut M, et al. Entrapped coronary catheter remnants and stents: must they be surgically removed? Tex Heart Inst J 2006; 33: 139-142.

17. Gabelmann A, Kramer S, Gorich J. Percutaneous retrieval of lost or misplaced intravascular objects. AJR Am J Roentgenol 2001; 176: 1509-1513.

18. Tateishi M, Tomizawa Y. Intravascular foreign bodies: danger of unretrieved fragmented medical devices. J Artif Organs 2009; 12: 80-89. 